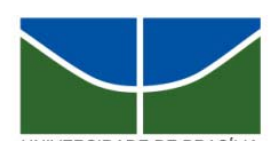

UNIVERSIDADE DE BRASÍLIA

Centro de Excelência em Turismo

Pós-graduação Lato Sensu

Curso de Especialização em Qualidade em Alimentos

FLÁVIA GODINHO FONSECA

PERFIL DA CONTAMINAÇÃO DE HORTALIÇAS MINIMAMENTE PROCESSADAS COMERCIALIZADAS NO DISTRITO FEDERAL

BRASÍLIA - DF 2009 
FLÁVIA GODINHO FONSECA

PERFIL DA CONTAMINAÇÃO DE HORTALIÇAS MINIMAMENTE PROCESSADAS COMERCIALIZADAS NO DISTRITO FEDERAL

Monografia apresentada ao Centro de Excelência em Turismo - UNB como requisito parcial para a obtenção de título de Especialista em Qualidade em Alimentos.

Orientador: Prof. Msc. Manoel Silva Neto

BRASÍLIA, ABRIL DE 2009 
Fonseca, Flávia Godinho.

Perfil da Contaminação de Hortaliças Minimamente processadas comercializadas no Distrito Federal / Fonseca, Flávia Godinho. - Brasília, 2009.

$33 \mathrm{f}$.

Monografia (especialização) - Universidade de Brasília, Centro de Excelência em Turismo, 2009.

Orientação: Manoel Silva Neto. 


\section{PERFIL DA CONTAMINAÇÃO DE HORTALIÇAS MINIMAMENTE PROCESSADAS COMERCIALIZADAS NO DISTRITO FEDERAL}

Monografia apresentada ao Centro de Excelência em Turismo - CET, da Universidade de Brasília, como requisito Universidade de Brasília, como requisito parcial à obtenção do grau de Especialista em Qualidade de Alimentos.

Aprovado em:

Professor Msc. Manoel Silva Neto

Professora Dra. Rita de Cássia Coelho de Almeida Akutsu

Professora MSc. Lívia de Lacerda de Oliveira Pineli

BRASILIA - DF 


\section{RESUMO}

As hortaliças minimamente processadas são definidas como produtos de origem vegetal, higienizados e embalados, que foram submetidos a processos técnicos, preservando suas características organolépticas naturais, tornando-se pronto para consumo in natura ou preparo culinário. Este trabalho teve como objetivo estabelecer um cenário dos dois anos do monitoramento da qualidade das hortaliças minimamente processadas comercializadas nos supermercados do Distrito Federal, 2007 a 2008. Os dados apresentados no trabalho foram obtidos de $100 \%$ dos laudos de análise emitidos pelo Laboratório Central de Saúde Pública do Distrito Federal. Durante os dois anos foram analisadas 36 amostras de hortaliças minimamente processadas, destas 25 (69\%) amostras apresentaram resultados condenatórios. Foram detectados não conformidades como: presença de fragmentos, ovos e larvas de insetos e insetos (58\%); coliformes a $45^{\circ} \mathrm{C}$ acima do limite máximo tolerado (8\%); ausência de número de registro no rótulo (19,5\%); ausência de data de validade com dia e mês (22\%); não declara nome e/ou endereço completo do fabricante $(5,5 \%)$. Das 36 amostras em apenas 4 foram realizados exames parasitológicos, destas 4 amostras em 1 amostra foi detectado a presença de cistos de Entamoeba Coli e de Balatidium Coli (25\%). Estes resultados demonstram a necessidade de um controle permanente por parte dos órgãos do governo em toda a cadeia produtiva de hortaliças minimamente processadas.

Palavras-chave: hortaliças minimamente processadas, qualidade, cadeia produtiva. 


\begin{abstract}
The vegetables minimally processed are defined as products of a vegetable origin, cleaned and packed, which were submitted to technical processes, preserving their natural organoleptics characteristics, making them ready to be consumed cooked or in natura. The objective of this work is to establish a scenery of two years of control of the quality of the vegetables minimally processed and commercialized in the supermarkets in Distrito Federal from 2007 to 2008. All the data here presented were obtained from the findings released by Central Laboratory of Public Health in Distrito Federal. During this period, 36 samples of these vegetables minimally processed were analyzed - 25 out of 36 samples, which means $69 \%$, presented condemned results. Non-conformity such as: fragments, ova and insect larva and insects (58\%); coliforms in $45^{\circ} \mathrm{C}$ above the maximum tolerable limit (8\%); the non existence of the number of registration on the label (19,5\%); the non existence of an expire date, month and day (22\%); the non existence of the complete name and address of the producer (5,5\%). Parasitological exams were made in 4 out of 36 samples. In one out of 4, was detected the presence of Entamoeba Coli and Balatidium Coli (25\%). These results indicate the necessity of a permanent control by the government officials in all the minimally processed productive vegetable chain.
\end{abstract}

Key words: vegetables minimally processed, quality, productive chain. 


\section{SUMÁRIO}

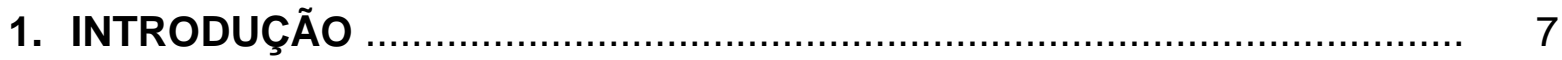

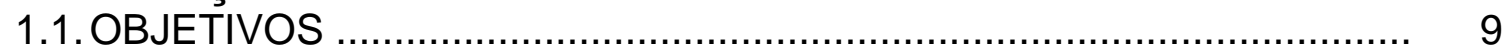

1.1.1. Objetivo Geral .............................................................. 9

1.1.2. Objetivos específicos ………............................................ 9

2. REVISÃO BIBLIOGRAFICA …............................................................... 10

2.1. ALIMENTO SEGURO …....................................................... 10

2.2. HORTALIÇAS MINIMAMENTE PROCESSADAS................................ 11

2.3. ETAPAS DO PROCESSAMENTO MÍMINO ........................................ 12

2.3.1. Boas Práticas Agrículas........................................................... 12

2.3.2. Operações do Processamento Mínimo........................................ 13

2.3.2.1. Manejo pós-colheita .................................................... 13

2.3.2.2. Seleção e Classificação...................................................... 14

2.3.2.3. Lavagem ............................................................. 14

2.3.2.4. Descascamento e Corte.................................................. 14

2.3.2.5. Enxágue .............................................................. 15

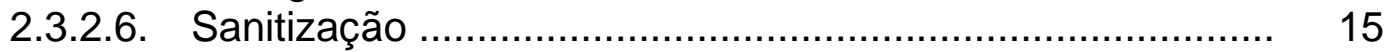

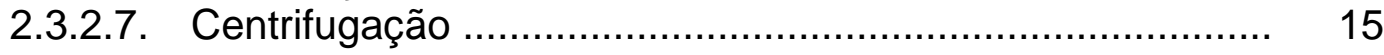

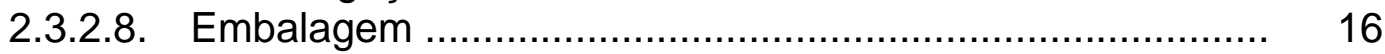

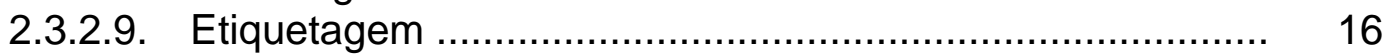

2.3.2.10. Armazenamento .......................................................... 16

2.3.3. Padrão de Identidade e Qualidade das Hortaliças Minimamente 17 Processadas

2.4. PROGRAMA DE VIGILÂNCIA SANITÁRIA …..................................... 19

3. MATERIAL E MÉTODOS …............................................................... 23

4. RESULTADOS E DISCUSSÃO …….................................................... 24

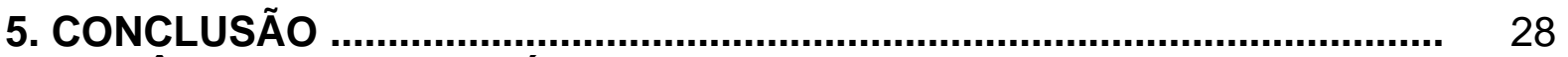

REFERÊNCIAS BIBLIOGRÁFICAS ....................................................... 30 


\section{INTRODUÇÃO}

Uma grande mudança nos padrões de consumo de frutos e hortaliças tem ocorrido durante a última década. A popularidade de frutos e hortaliças frescos está aumentando em relação ao consumo de produtos embalados. Ao mesmo tempo, consumidores estão desejosos por produtos que tenham ótima qualidade e que sejam convenientes no preparo e na hora de servir.

A procura por alimentos saudáveis tem aumentado a cada dia. Porém, o tempo disponível para o preparo dos alimentos tem sido reduzido, devido à vida agitada nas cidades. Frutos e hortaliças minimamente processados são particularmente convenientes neste contexto.

Os produtos minimamente processados são aqueles submetidos a operações de limpeza, lavagem, seleção, descascamento, corte, embalagem e armazenamento, mas que apresentam qualidade semelhante à do produto fresco (CHITARRA, 1998). Apresentam grande potencial de comercialização em decorrência da demanda constante e crescente por alimentos com características de produto natural com alta qualidade de preparo fácil e que tenham condições higiênicas garantidas para o consumo seguro, sem causar danos à saúde do consumidor.

O maior produtor e consumidor de hortaliças minimamente processadas são os Estados Unidos, com um volume produzido em 1998 de mais de 15 milhões de toneladas, movimentando mais de 8 bilhões de dólares. No Brasil, frutas e vegetais minimamente processados foram timidamente introduzidas no mercado no início da década de 1990 no estado de São Paulo. Estima-se hoje um crescimento anual próximo a 20\%. No Distrito Federal o consumo atinge cerca de 200 toneladas 
por mês, os quais são comercializados em sua maioria nas redes de hipermercado e supermercados (NASCIMENTO et al., 2009).

Os consumidores de hortaliças minimamente processadas são seletivos e exigentes, têm no produto as vantagens como: a praticidade, pois o produto vem pronto para consumo; alta qualidade sanitária; manutenção das características sensoriais e nutricionais do vegetal fresco; eliminação de desperdício; aquisição apenas da parte comestível do vegetal; possibilidade de compra de menores quantidades; possibilidade de conhecer a procedência do produto e de escolher marcas. Em relação às vantagens para o produtor são: agregar valor ao produto; eliminar intermediários; redução de perdas; e obter preços constantes ao longo do ano sem depender de cotações sazonais $(\mathrm{ABH}, 2009)$.

A preocupação em relação à qualidade das hortaliças minimamente processadas é principalmente de natureza microbiológica, pois esse produto sofre operações que aumentam o risco de contaminação. Esses microorganismos podem ser deteriorantes, que influenciam nas alterações sensoriais do produto, ou patogênicos, que podem causar enfermidade ou dano aos seres humanos (PINHEIRO et al., 2005). 


\subsection{OBJETIVOS}

\subsubsection{OBJETIVO GERAL}

O objetivo geral deste trabalho é estabelecer um cenário dos dois anos do monitoramento da qualidade das hortaliças minimamente processadas comercializadas no Distrito Federal.

\subsubsection{OBJETIVOS ESPECÍFICOS}

- Identificar as marcas comercializadas no Distrito Federal de hortaliças minimamente processadas.

- Caracterizar a produção de hortaliças minimamente processadas no Distrito Federal.

- Realizar levantamento dos laudos laboratoriais de análises de hortaliças minimamente processadas do Programa de Vigilância Sanitária.

- Analisar os laudos laboratoriais. 


\section{REVISÃO BIBLIOGRAFICA}

\subsection{ALIMENTO SEGURO}

O alimento é toda substância ou mistura de substâncias destinadas a fornecer, ao organismo vivo, os elementos essenciais à sua formação, manutenção e desenvolvimento. Como organismo vivo, o microrganismo depende deste substrato para o seu crescimento, tornando assim competidores permanentes - homem e microorganismo. Assim, o homem usa de seu conhecimento para eliminar ou reduzir aqueles que por ventura ofereça risco à sua saúde e "alimenta" aqueles que são benéficos à mesma (SILVA, 2000).

A questão da qualidade alimentar sempre foi uma preocupação da sociedade e dos governos em todo o mundo. Na década de 1970 a preocupação maior era com os aditivos alimentares intencionais, na década de 1980 foram os praguicidas e na década de 1990 foram assuntos relacionados com a biotecnologia (XIMENES, 2005).

Segundo FORSYTHE (2002), a qualidade de um alimento pode ser medida por meio de comparação contra um padrão considerado excelente, o qual é satisfatório tanto para o produtor como para o consumidor. O objetivo da garantia de qualidade é assegurar que um determinado produto seja produzido todas às vezes, o mais próximo possível, de um padrão ideal. A qualidade pode ser avaliada por meio dos sentidos, pela composição química, pelas propriedades físicas e pela flora microbiológica tanto quantitativa como qualitativa. A produção de alimentos seguros é responsabilidade de todos no sistema de produção. 
A definição de alimentos seguros é dada a partir do que constitui um risco significativo. Risco pode ser definido como uma função da probabilidade da ocorrência de um evento indesejável, com severidades diferenciadas em relação aos efeitos adversos à saúde humana, à propriedade ou ao ambiente (XIMENES, 2005). O público em geral, por exemplo, acredita que alimentos seguros significam risco igual à zero, enquanto um produtor de alimentos deve considerar o que é um risco aceitável. Os riscos de ocorrência de doenças transmitidas por alimentos devem ser reduzidos ao máximo durante a sua produção para um risco aceitável (FORSYTHE, 2002).

\subsection{HORTALIÇAS MINIMAMENTE PROCESSADAS}

O mercado de produtos hortifrutículas frescos tem crescido de maneira significativa nesta última década. Nos últimos anos, tem-se enfatizado a necessidade do consumo de frutas e hortaliças frescas, buscando-se uma dieta saudável, ao mesmo tempo uma demanda crescente de alimentos mais convenientes, frescos, que sejam menos processados e estejam prontos para o consumo (REIS, 2003).

O segmento de frutas e hortaliças que mais cresce no mercado é o minimamente processado (BERBARI et al., 2001). As hortaliças minimamente

processadas são definidas como produtos de origem vegetal, higienizados e embalados, que foram submetidos a processos técnicos, preservando suas características organolépticas naturais, tornando-os prontos para consumo in natura ou preparo culinário (SILVA, 2008). 
O processamento mínimo de frutas e hortaliças é definido como a operação que elimina as partes não comestíveis dos mesmos, como casca, talos e sementes, seguidos do preparo em tamanhos menores e prontos para consumo imediato, sem que o vegetal perca a condição de produto fresco, com qualidade e garantia de sanidade (SILVA, 2008).

As operações para o processamento de vegetais levam a injúrias no tecido com conseqüente aumento na síntese do hormônio vegetal etileno e aumento da taxa respiratória, antecipando o amadurecimento e a senescência do tecido. Além disso, a eliminação da casca, que é uma barreira física do fruto, e a liberação do exsudado rico em nutrientes, como resultado de cortes, facilitam a colonização pelos microorganismos, levando a perecibilidade dos vegetais processados quando comparados com o produto in natura (PEREIRA, 2004).

Algumas ferramentas de qualidade, como Boas Práticas Agrícolas (BPA), Boas Práticas de Fabricação - BPF e o Programa de Análise de Perigos e Pontos Críticos de Controle - APPCC, devem ser adotadas com a finalidade de minimizar a contaminação das hortaliças minimamente processadas em toda a cadeia produtiva, do campo a mesa do consumidor (VANETTI, 2008).

\subsection{ETAPAS DO PROCESSAMENTO MÍNIMO}

\subsubsection{Boas Práticas Agrícolas}

As boas práticas agrícolas são indispensáveis para a obtenção de uma matéria-prima de qualidade, principalmente do ponto de vista das contaminações por produtos químicos e de natureza microbiológica. As principais fontes de 
contaminação microbiológica são o uso inadequado de esterco não curtido na adubação, a água de irrigação contaminada e a higiene dos trabalhadores. O uso indiscriminado de agrotóxicos, sem obedecer ao período de carência dos mesmos, pode provocar a presença de resíduos químicos em concentrações superiores aos limites recomendados pela legislação, e, conseqüentemente, oferecer riscos ao consumidor. Medidas de controle preventivo como o cultivo protegido, a higiene no campo, com a remoção e destruição de material vegetal como folhas, ramos e frutos doentes e infectados, bem como espaçamento adequado e boa condução das árvores, adubação balanceada em nutrientes, reduzem o ataque de pragas e doenças e aplicações de agrotóxicos, aumentando a qualidade e o período de conservação pós-colheita dos mesmos.

\subsubsection{Operações de Processamento Mínimo}

O processo de produção dos minimamente processados passa por várias etapas, como manejo pós-colheita, seleção, lavagem, corte ou fatiamento, enxágüe, sanitização, centrifugação, seleção, embalagem e armazenamento (EMBRAPA, 2003). O resultado, desde que seja priorizada a qualidade, é um produto sem microrganismos patogênicos, e com atributos de consistência, coloração, frescor e ausência de defeitos (DURIGAN, 2004).

2.3.2.1. Manejo pós-colheita: Depois de colhidas, as hortaliças devem ser transportadas imediatamente para a unidade processadora ou mantidas em condições que evitem murchas ou ressecamento. O ideal seria que durante a colheita já se fizesse uma limpeza das partes não 
aproveitáveis, com lavagem e pré-resfriamento, ainda no campo. O transporte e outras operações como carga e descarga, assim como a recepção devem ser cuidadosamente realizadas, evitando-se choques bruscos e fortes (DURIGAN, 2004).

2.3.2.2. Seleção e Classificação: Nesta etapa são eliminados materiais impróprios para consumo, apodrecidos ou atacados por insetos, assim como partes que não serão processadas, como pedúnculos, talos, restos vegetais e partes estragadas ou velhas (DURIGAN, 2004). Em seguida, faz-se a classificação por aparência e tamanho, a fim de padronizar a matéria-prima para o tipo de processamento a que se destina (PINTO, 2007).

2.3.2.3. Lavagem: Esta etapa consiste em lavar a matéria-prima em água potável, com objetivo de remover todas as sujidades, insetos e outras impurezas, que por ventura, ficam aderidas à superfície (MORETTI et al., 2006). Esta etapa contribui com a redução da flora bacteriana, no entanto, quando não executada corretamente, pode agir de forma inversa, difundindo e incrementando a contaminação microbiana, como ocorre quando se reutiliza a água de lavagem (MAISTRO, 2001).

2.3.2.4. Descascamento e Corte: Esta etapa pode ser manual ou mecânica (VITTI, et al., 2004). É um momento crítico dentro de processamento mínimo, pois os danos sofridos pelos vegetais levam à liberação de sumo rico em nutrientes e a um aumento da respiração dos tecidos, o 
que permite um desenvolvimento microbiano mais rápido e maiores populações de microorganismos tanto no produto quanto no equipamento utilizado no processo. Além disso, estas operações têm um potencial de recontaminar o produto, em virtude da alta manipulação em que são submetidos (PINTO, 2007).

2.3.2.5. Enxágüe: consiste na imersão rápida do produto processado em água a baixa temperatura (4-6 $\left.{ }^{\circ} \mathrm{C}\right)$, para remoção do suco celular liberado e resfriamento. Esta é uma maneira de inibir o crescimento de microorganismos e evitar que a matéria-prima orgânica liberada reaja com o cloro livre da solução sanitizante, na próxima etapa, formando compostos indesejáveis e reduzindo a eficiência da sanitização (MORETTI et al., 2006).

2.3.2.6. Sanitização: Esta etapa consiste na imersão do produto cortado em solução com $150 \mathrm{mg} / \mathrm{L}$ a $200 \mathrm{mg} / \mathrm{L}$ de cloro livre, próximo a $5^{\circ} \mathrm{C}$, por cerca de 10 minutos (MORETTI et. al, 2006). A solução de cloro deve ser obtida usando-se sanitizantes próprios para alimentos e permitidos pela Agência Nacional de Vigilância Sanitária.

2.3.2.7. Centrifugação: Esta etapa é necessária para a retirada do excesso de água presente no alimento, após a lavagem e sanitização (DURIGAN, 2004). Esta é outra etapa crítica dentro do fluxograma de processamento, pois deve evitar a disponibilidade de água livre no produto e o conseqüente desenvolvimento de microorganismos (LIMA et al., 2006). Segundo MORETT et al. (2006), o tempo ideal de 
centrifugação é aquele em que toda a água que foi adicionada ao produto por ocasião das imersões seja retirada, tomando cuidado para não desidratá-los. A centrifugação, dependendo da intensidade utiliza, poderá causar injúrias ao produto, e, assim, promover uma deterioração mais rápida do mesmo, portanto, recomenda-se que quando realizada, o seja de forma suave (MAISTRO, 2001).

2.3.2.8. Embalagem: A embalagem pode ser realizada em sacos plásticos, em bandejas com cobertura plástica ou outros recipientes de plástico transparente (LIMA, et al., 2006). Há um tipo de embalagem adequada para cada produto, a qual pode contribuir para controlar de maneira favorável a atmosfera da embalagem e permitir a injeção de misturas gasosas conservadoras, que reduzirão a respiração, aumentando a vida útil dos produtos.

2.3.2.9. Etiquetagem: $O$ produto deve ser imediatamente etiquetado após a pesagem para evitar que o produto saia da cadeia de frio. Deve-se também, fazer a separação por lotes, em função da distribuição. Isto evita que as embalagens sejam manuseadas várias vezes, o que pode danificar o produto e diminuir sua vida de prateleira (DURIGAN, 2004).

2.3.2.10. Armazenamento: A fim de manter a qualidade e a segurança microbiológica do alimento minimamente processado, realiza-se seu armazenamento a uma temperatura entre $0^{\circ} \mathrm{C}$ e $5^{\circ} \mathrm{C}$. 
Depois de embalado e etiquetado, o produto deve ser armazenado em câmaras providas de isolamento interno e com máquinas produtoras de frio capazes de mantê-los refrigerados à temperatura desejada (DURIGAN, 2004). Um dos principais fatores relacionados com a manutenção da qualidade do produto minimamente processado é o controle rigoroso da temperatura durante o processo de produção bem como durante a fase de armazenamento e comercialização (NASCIMENTO et al., 2003).

\subsubsection{Padrão de Identidade e Qualidade das Hortaliças Minimamente Processadas.}

A qualidade microbiológica dos alimentos minimamente processadas está relacionada à presença de microrganismos deteriorantes que influenciam nas alterações sensoriais do produto. Mas, a maior preocupação está relacionada a sua segurança, não apresentando contaminação por agentes químicos, físicos e microbiológicos em concentrações prejudiciais a saúde (PINHEIRO et al., 2005).

A determinação da incidência de microrganismos deteriorantes e patogênicos nestes produtos, além de ser uma fonte de dados para especificação de padrões microbiológicos, serve de subsídios para a implantação das boas práticas de fabricação (PINHEIRO et al., 2005).

Os microrganismos patogênicos diretamente associados a hortaliças minimamente processadas são: Listeria monocytogenes, Escherichia coli, Shigella, Salmonella, Clostridium botulinum, Clostridium perfringens, Staphylococcus aureus, Campilobacter, Vibrio Species, Vírus e parasitas (SILVA et al., 2006). 
A garantia de que o produto processado tenha qualidade e seja seguro para a saúde do consumidor requerer o desenvolvimento de uma tecnologia avançada que considere aspectos fisiológicos, tecnológicos, sensoriais e microbiológicos do produto gerado (ARTECHE, 2006).

No processamento mínimo, os obstáculos para eliminação de microrganismos e, ou, controles do crescimento microbiano são poucos e incluem, principalmente, a qualidade da matéria-prima, a lavagem, o uso de sanitizantes, embalagens em atmosfera modificada e refrigeração (SILVA et al., 2006).

O Brasil não dispõe de normas especificas para a comercialização de hortaliças minimamente processadas. Desta maneira, são utilizados os mesmos padrões para alimentos in natura. A aparência, o sabor, a coloração, a textura e as características microbiológicas influenciam diretamente na qualidade e na segurança do produto (MORETTI, 2003).

Os padrões microbiológicos para alimentos são estabelecidos pela Resolução - RDC no 12, de 2 de janeiro de 2001. As hortaliças minimamente processadas são inseridas no grupo de fruta frescas, in natura, preparadas (descascadas ou selecionadas ou fracionadas), sanificadas, refrigeradas ou congeladas, para consumo direto. A tolerância máxima para amostra indicativa é de $5 \times 10^{2}$ NMP. $g^{-1}$ ou UFC. $g^{-1}$ de coliformes a $45^{\circ} \mathrm{C}$ e ausência de Salmonella sp em 25g (PINHEIRO et al., 2005).

Os padrões macroscópicos e microscópicos de frutas e hortaliças minimamente processadas no âmbito do Distrito Federal são estabelecidos pelo Decreto n. ${ }^{0}$ 19.339, de 19 de junho de 1998, que regulamenta a inspeção sanitária e industrial dos produtos de origem vegetal no Distrito Federal. Este decreto considera 
impróprios para consumo produtos de origem vegetal que contendo quaisquer sujidades. Outra legislação que trata sobre este assunto, é a Resolução RDC No 175, de 8 de julho de 2003, que aprova o regulamento técnico de avaliação de matérias macroscópica e ou microscópica prejudicial à saúde humana em alimentos embalados. Esta resolução considera como matéria prejudicial à saúde humana:

- Insetos, em qualquer fase de desenvolvimento, vivos ou mortos, inteiros ou em partes, reconhecidos como vetores mecânicos;

- Outros animais vivos ou mortos, inteiros ou em partes, reconhecidos como vetores mecânicos;

- Parasitos;

- Excrementos de insetos e ou de outros animais;

- Objetos rígidos, pontiagudos e ou cortantes, que podem causar lesões no consumidor.

\subsection{PROGRAMA DE VIGILÂNCIA SANITÁRIA - PVS}

A preocupação com a Segurança Alimentar cresceu especialmente nos últimos anos, gerando varias discussões entre organizações governamentais, acadêmicos e indústrias de alimentos, sobre programas que assegurem à população o acesso a produtos que não sejam prejudiciais à saúde (SHINOHARA, 2003). A Diretoria de Vigilância Sanitária em parceria com o Laboratório Central de Saúde Pública do Distrito Federal (LACEN-DF) elaboram anualmente um Programa que monitora a identidade e a qualidade de produtos comercializados no Distrito Federal, intitulado Programa de Vigilância Sanitária (PVS). 
A vigilância sanitária do Distrito Federal até o ano de 1978, em que se refere ao controle de produtos, foi desenvolvida de forma aleatória por parte do então Departamento de Fiscalização de Saúde (DpFS), sendo fator básico para a apreensão de produtos as condições de suas características organolépticas (DISTRITO FEDERAL, 1994).

Com a criação do então Instituto de Saúde do Distrito Federal (ISDF), que mantém até hoje como um de seus principais objetivos o Controle de Qualidade dos produtos consumidos no DF, as ações de Vigilâncias Sanitárias passaram a ser desenvolvidas pelo DpFS e ISDF (DISTRITO FEDERAL, 1994).

$\mathrm{Na}$ necessidade de ordenar estes trabalhos, em 1985, foi criado o "Programa de Vigilância Sanitária" - Portaria n. 02 - SES - DF de 27 de fevereiro de 1985.

Com o efetivo entrelaçamento das ações de Vigilância Sanitária e Epidemiológicas, o Programa passou por uma reestruturação no ano 1994 - Portaria n. ${ }^{\circ} 48$ - SES -DF, de 29 de dezembro de 1994.

Segundo a Portaria, o Programa de Vigilância Sanitária tem como objetivo geral: Promover atividades integradas de Vigilância à Saúde, visando a promoção e proteção da saúde. E seus objetivos específicos são:

- Exercer o controle e a fiscalização sobre os Alimentos, Bebidas, Medicamentos, Correlatos, Saneantes domissanitários, cosméticos e outros, de forma a garantir ao consumidor produtos de boa qualidade.

- Exercer o controle e fiscalização dos ambientes e serviços utilizados pela população, de forma a garantir a proteção à saúde. 
- Promover a integração das atividades de fiscalização de saúde, Vigilância epidemiológica e laboratório de saúde pública.

- Desenvolver de forma ordenada e permanente, as atividades de fiscalização, vigilâncias epidemiológicas e laboratoriais.

- Promover as ações de caráter educativo de forma a complementar as atividades de Vigilância Sanitária.

- Definir normas e procedimentos para a operacionalização sistemática do Programa.

O Programa de Vigilância Sanitária baseia-se na coleta e análise de produtos provenientes do comércio, ambiente e serviços do Distrito Federal, com objetivo de controlar e prevenir os riscos à saúde da população (DISTRITO FEDERAL, 1994).

A avaliação analítica dos produtos que fazem parte do Programa Vigilância Sanitária se dá em consonância com a Lei no 6437 de 1977 e o Decreto-lei nº 986 de 1969, que instituem a realização de análises para avaliação laboratorial. O objetivo desta avaliação é verificar a conformidade do produto com as especificações contidas no rótulo e com as normas de qualidade mínima.

A função principal das análises laboratoriais é fornecer subsídios aos órgãos fiscalizadores, confirmando suspeitas ou dirimindo dúvidas quanto à qualidade mínima do produto ou da matéria-prima estabelecida em lei.

A apreensão de amostra deve ser realizada seguindo as normas legais, mesmo em casos de apreensões programadas, ou seja, quando não existe suspeita aparente. Pois, na falta do respaldo legal, no caso de constatação de alguma 
irregularidade no produto as medidas corretivas terão que esperar nova apreensão e haverá retardamento na superação do problema (ROZENFELD, 2000).

Considerando o objetivo do programa que é monitorar por meio de análises laboratoriais os produtos, são utilizadas algumas modalidades de análise. Sendo a análise fiscal e de orientação. A análise fiscal avaliará a capacidade de se seguir produzindo, conforme o estabelecido nos termos do registro e/ou notificação. A análise de orientação, que não é prevista em lei, é utilizada nas análises dos produtos provenientes do Subprograma de Controle de Ambientes, por exemplo, água para consumo humano e mecha de esgoto.

No caso das hortaliças minimamente processadas que é o foco deste trabalho a modalidade de analise empregada é a fiscal. 


\section{MATERIAL E MÉTODO}

Os dados apresentados no trabalho foram obtidos de $100 \%$ dos laudos de análise emitidos durante os dois anos de monitoramento da qualidade das hortaliças minimamente processadas. As 36 amostras foram coletadas de forma aleatória em gôndolas de supermercados do Distrito Federal. Estes produtos são dentre os alimentos monitorados pelo Programa de Vigilância Sanitária, parceria esta entre a Diretoria de Vigilância Sanitária e Laboratório Central de Saúde do Distrito Federal.

As amostras passaram por análises de rotulagem, sensorial, microscópica, microbiológica e parasitológica, esta última, por apenas 4 amostras. 


\section{RESULTADOS E DISCUSSÕES}

No período compreendido entre 2007 a 2008 foram analisadas pelo Programa 36 amostras. Das 36 amostras 25 (69\%) apresentaram resultados condenatórios.

Nas 25 amostras condenadas foram detectados não conformidades como: presença de fragmentos, ovos e larvas de insetos e/ou insetos; coliformes a $45^{\circ} \mathrm{C}$ acima do limite máximo tolerado; presença de cistos de Entamoeba Coli e de Balatidium coli; ausência de número de registro no rótulo; ausência de data de validade com mês e ano; não declara nome e/ou endereço completo do fabricante (figura 1).

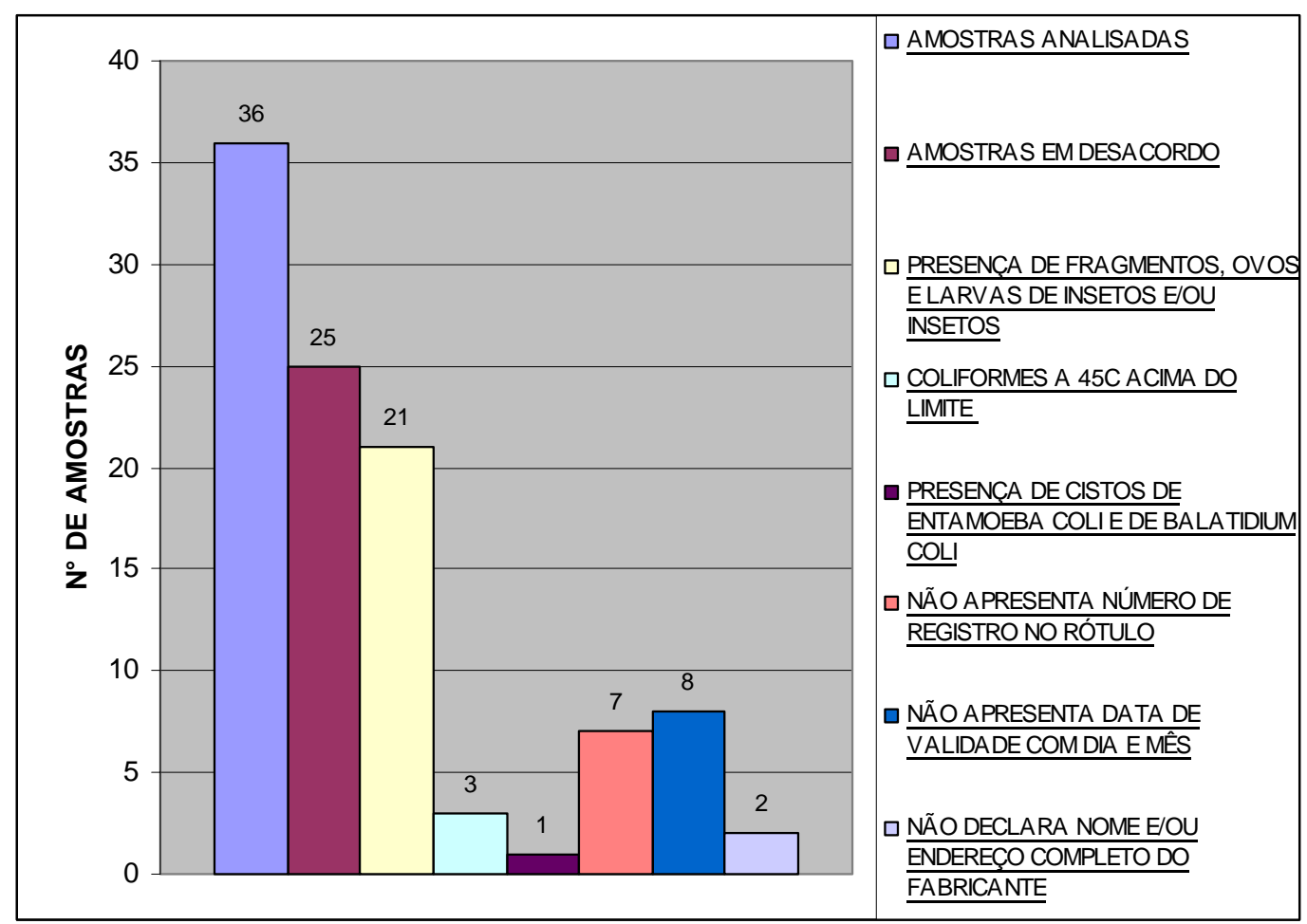

Figura 1. Resultados do monitoramento da qualidade de hortaliças minimamente processadas comercializadas nos supermercados do Distrito Federal - 2007/2008. 
Das 25 amostras condenadas em 21 foram detectadas a presença de fragmentos, ovos e larvas de insetos e insetos, contrariando o art. 40 do Decreto n. ${ }^{\circ}$ 19.339, de 19 de junho de 1998 (anexo I). Este resultado confirma o que diz o SEBRAE (2008) que equipamentos e processos inadequados para a remoção de insetos e outros macro-organismos, a pouca disponibilidade de equipamentos nacionais são um dentre os gargalos importantes do processamento mínimo. Este tipo de contaminante demonstra falhas na etapa de higienização do processamento mínimo. Como medida de minimizar este tipo de contaminação o SEBRAE (2008) indica a adoção de pré-lavagem imediatamente após a colheita. A inexistência de detergente próprio para o uso em alimentos dificulta ainda mais a remoção destes contaminantes físicos.

Os resultados das análises microbiológicas mostraram que 3 amostras, todas de couve picada, apresentaram coliformes a $45^{\circ} \mathrm{C}$ acima do limite máximo tolerado, sendo duas analisadas em 2007 e a terceira no ano de 2008. Estas amostras estão em desacordo com a Resolução RDC no 12 de 02 de janeiro de 2001. O índice de coliforme a $45^{\circ} \mathrm{C}$ é empregado como indicador de contaminação fecal, por isso são considerados como bons indicadores de práticas de higiene e processos de produção inadequados (PAULA et al., 2009).

A presença de coliformes a $45^{\circ}$ acima do limite acima do tolerado em hortaliças minimamente processadas pode indicar, além de práticas de higiene e processos de produção imprópria, o armazenamento em temperatura inadequada. Segundo Nascimento et al. (2003), a temperatura de armazenamento de hortaliças minimamente processadas expostas em gôndolas refrigeradas de 4 hipermercados e 4 supermercados do Distrito Federal foi superior a $10^{\circ} \mathrm{C}$, muito acima dos $5^{\circ} \mathrm{C}$ recomendados para armazenamento e comercialização destes produtos. 
Em nenhuma das amostras de hortaliças minimamente processadas analisadas foram detectadas a presença de Salmonella sp. Nas amostras de 2007, além de coliformes a $45^{\circ} \mathrm{C}$, Salmonella $s p$ também foi pesquisada a presença de Escherichia Coli, tendo como resultado ausência para todas as amostras.

Das amostras analisadas, apenas em 4 delas foram realizados exames parasitológicos. Das amostras analisadas, 1 amostra foi detectado a presença de cistos de Entamoeba coli e Balantidium coli. A presença Entamoeba coli e Balantidium coli demonstra a contaminação fecal de origem humana, e, ou, animal. Os seus cistos, embora não sejam considerados patogênicos apresentam grande valor como indicadores de contaminação fecal de origem humana nas águas de irrigação (FILHO, 2008).

Das 25 amostras condenadas 07 não apresentavam no rótulo número de registro no órgão competente. O órgão do governo responsável pelo registro das hortaliças minimamente processadas no Distrito Federal é a Secretaria de Estado de Agricultura, Pecuária e Abastecimento. Este resultado demonstra a inobservância da Lei n. ${ }^{\circ}$ 1.671, de 23 de setembro de 1997 (anexo II), que estabelece que os estabelecimentos de processamento de produtos de origem vegetal somente poderão funcionar mediante prévio registro na Secretaria de Estado de Agricultura, Pecuária e Abastecimento.

Algumas irregularidades de rotulagem também foram detectadas como: a ausência de data de validade com dia e mês e não declarava nome e/ou endereço completo do fabricante, contrariando a Resolução - RDC n. ${ }^{\circ} 259$, de 20 de setembro de 2002. Em relação à data de validade, o subitem da 6.6.1, alínea "b", da referida resolução estabelece que o prazo de validade deve constar de pelo menos: o dia e o 
mês para produtos que tenham prazo de validade não superior a três meses, que é o caso das hortaliças minimamente processadas. 


\section{CONCLUSÃO}

Os resultados encontrados no presente trabalho levam as seguintes conclusões:

- As hortaliças minimamente processadas ocupam um importante segmento na indústria atual. Estes produtos não estão isentos nem de perigos nem de riscos, sendo então importante assegurar em todo elo da cadeia produtiva ferramentas disponíveis para inocuidade desses alimentos.

- A qualidade das hortaliças minimamente processadas comercializadas nos supermercados do Distrito Federal encontra-se comprometida, considerando que nestes dois anos do programa $69 \%$ das amostras analisadas encontravam-se não conformes com a legislação vigente, sendo assim distribuídas:

o presença de fragmentos, ovos e larvas de insetos e insetos (58\%);

o coliformes a $45^{\circ} \mathrm{C}$ acima do limite máximo tolerado (8\%);

o presença de Entamoeba Coli e de Balatidium Coli (25\%), considerando que apenas 4 amostra passaram por análise de parasitologia;

o ausência de número de registro no rótulo (19,5\%);

o ausência de data de validade com dia e mês (22\%);

o não declara nome e/ou endereço completo do fabricante (5,5\%).

- A presença de fragmentos, larvas e ovos de insetos e insetos, mesmo quando não reconhecido como vetor mecânico, demonstra a inobservância das boas práticas de fabricação, o que caracteriza desvio de qualidade. 
Diante dos resultados apresentados é imprescindível a intervenção dos órgãos de fiscalização, neste caso, Vigilância Sanitária e Secretaria de Estado de Agricultura, Pecuária e Abastecimento, em toda a cadeia produtiva de frutas e hortaliças minimamente processadas. 


\section{REFERÊNCIAS BIBLIOGRAFICAS}

ABH - ASSOCIAÇÃO BRASILEIRA DE HORTICULTURA. Cresce o Mercado de Hortaliças Processadas no Brasil. Disponível em: http://www.abhorticultura.com.br. Acesso em: 09/02/2009.

ARTECHE, I. E. B. Tipificação de Produtores, Descrição de Métodos de Processamento Mínimo e Aspectos Bromatológicos de Couve (Brassica oleracea var. acephala L.) Minimamente Processada. Disponível em: http://www.lume.ufrgs.br/bitstream/handle/10183/8129/000568392.pdf?sequence=1. Acesso em: 10/04/2009.

BERBARI, S. A. G.; PASCHOALINO, J. E.; SILVEIRA, N. F. A. Efeito do Cloro na Água de Lavagem para Desinfecção de Alface Minimamente Processada. Rev. Cienc. Tecnol. Aliment., Campinas - SP, 21(2): 197-201, maio-ago. 2001.

CENCI, S. A. Boas Práticas de Pós-colheita de Frutas e Hortaliças na Agricultura Familiar. 2006. Disponível em: http://www.ctaa.embrapa.br/projetos/fhmp/arquivos/BOAS\%20PRATICAS\%20DE\%2 OPOS-COLHEITA\%20DE\%20FRUTAS\%20E\%20HORTALICAS.pdf. Acesso em: 23/03/2009.

CHITARRA, M. I. F. Processamento Mínimo de Frutas e Hortaliças. Viçosa: Centro de Produções Técnicas. 1998. 88p.

DURIGAN, J. F. Processamento mínimo de frutas e hortaliças. Fortaleza: Instituto Frutal, 2004.

JUNQUEIRA, A. M. R., RIBEIRO, A. C. F., GOMES, R. A., PERES, R. M. Hortaliças minimamente processadas no Distrito Federal: visão do segmento varejista. 2003. http://www.abhorticultura.com.br/biblioteca/arquivos/Download/Biblioteca/olec4005.p df. Acesso em: 09/0/2009. 
JUNQUEIRA, A.M.R. Organização de Plataformas - Agroindústrias de Produtos de Origem Vegetal. UnB - FAV-NUCOMP/FAPDF, BRASILIA-DF, 2002. 150P.

LIMA, L. C. de O.; SIQUEIRA, H. H.; BOTELHO, M. Fluxo do Processamento Mínimo. IV ENCONTRO NACIONAL SOBRE PROCESSAMENTO MÍNIMO DE FRUTAS E HORTALIÇAS. Palestras, Universidade de São Paulo. São Paulo, 2006, p. 240.

MAISTRO, L. C. Alface Minimamente Processada: Uma revisão. Rev. Nutr., Campinas - SP, v.14, n.3, 219-224p, set./dez., 2001.

MORETTI, C. L. 2003. Boas práticas agrícolas para a produção de hortaliças. Disponível em: http://www.feagri.unicamp.br/tomates/pdfs/pal05.pdf. Acesso em: 23/03/2009.

MORETTI, C. L.; PUSCHMANN, R. Processamento Mínimo de Hortaliças. In: IV ENCONTRO NACIONAL SOBRE PROCESSAMENTO MÍNIMO DE FRUTAS E HORTALIÇAS. Palestras, Universidade de São Paulo. São Paulo, 2006, p. 234.

NASCIMENTO, E. F.; MORETTI, C. L.; ZUCHETTO, M. C.; MATTOS, L. M. 2003. Avaliação da temperatura de comercialização de hortaliças minimamente processadas no mercado varejista do Distrito Federal. Disponível em: http://www.abhorticultura.com.br. Acesso em: 09/02/2009.

PAULA, N. R. F.; VILAS BOAS, E. V. B.; RODRIGUES, L. J.; CARVALHO, R. A.; PICCOLI, R. H. Qualidade de Produtos Minimamente Processados e comercializados em Gôndolas de Supermercados nas Cidades de Lavras - MG, Brasília - DF e São Paulo - SP. Rev. Ciênc. Agrotec., Lavras - MG, v. 33, n. 1, p. 219-227, jan./fev. 2009.

PEREIRA, K. S.; PEREIRA, J. L.; MIYA, N. T. N. Análises Microbiológicas de Manga, Cultivar Palmer, Congelada e Minimamente Processada. Rev. Higiene Alimentar, São Paulo - SP, vol. 18, n. 119, p. 47-50, 2004. 
PINHEIRO, N. M. S.; FIGUEIREDO, E. A. T.; FIGUEIREDO, R. W.; MAIA, G. A.; SOUZA, P. H. M. Avaliação da qualidade microbiológica de frutos minimamente processados comercializados em supermercados de fortaleza. Rev. Bras. Frutic., Jaboticabal - SP, v. 27, n. 1, p. 153-156, 2005.

PINTO, A. R. C. Qualidade microbiológica de frutas e hortaliças minimamente processadas: uma revisão. 2007. 36. : il. Monografia (especialização) Universidade de Brasília, Centro de Excelência em Turismo, Brasília - DF, 2007.

REIS, K. C; PEREIRA, J.; VALLE, R. H. P.; NERY, F. C. Avaliação da Qualidade Microbiológica de Minimilho (ZEA MAYS) Minimamente Processados. Rev. Higiene Alimentar, São Paulo - SP, v. 17, n. 110, p. 66-68, 2003.

ROZENFELD, S. (org.). Fundamentos da vigilância sanitária. Rio de Janeiro: Editora FIOCRUZ, 2000.

SEBRAE. Iniciando um pequeno grande negócio agroindustrial: hortaliças minimamente processadas/Embrapa Hortaliças, Serviço Brasileiro de Apoio às Micro e Pequenas Empresas. - Brasília: Embrapa Informação Tecnológica, 2003.

SEBRAE. Hortaliças Minimamente Processadas: Estudos de Mercado SEBRAE, ESPM 2008: Relatório Completo. Disponível em: http://www.biblioteca.sebrae.com.br/bds/BDS.nsf/0883FDA8A4AF0BAE832574DC00 4682B0/\$File/NT0003907E.pdf. Acesso em: 02/04/2009.

SHINOHARA, N. K. S.; LIMA, E. C.; MELO, R. G.; STAMFORD, T. L. M. Potencial Patogênico do Clostridium Perfringens em Alimentos. Rev. Higiene Alimentar, São Paulo - SP, v. 17, n. 106, p. 72-77, 2003.

SILVA, J. A. Tópicos da tecnologia dos alimentos. São Paulo: Editora Varela, 2000 , p. 5.

SILVA, E. O; BASTOS, M. S. R.; ALVES, R. E.; SOARES, N. F. F.; PUSHMANN, R. Segurança Microbiológica em Frutas e Hortaliças Minimamente Processadas. In: I SIMPÓSIO IBERO AMERICANO DE VEGETAIS FRESCOS CORTADOS, San Pedro - SP. Brazil, Abril. 2006. 
SILVA, P. R. Uma Abordagem sobre o Mercado de Hortaliças Minimamente Processadas. Rev. Informações Econômicas, São Paulo - SP, v. 38, n.4, abril. 2008.

VITTI, M. C. D.; KLUGE, R. A.; GALLO, C.R; MORETTI, C.L.; JACOMINO, A. P. Efeito do momento de sanitização sobre atributos físico-químicos $e$ microbiológicos de beterrabas minimamente processadas. Horticultura Brasileira, Brasília, v. 22, n.4, p. 718-721, out-dez 2004.

XIMENES, M.I. N. Toxicologia dos Alimentos. Resumo Teórico. $2^{\circ}$ semestre de 2005. Faculdades Integradas da Terra de Brasília. Trabalho não publicado. 